\title{
Tin-free Alternatives to the Barton- McCombie Deoxygenation of Alcohols to Alkanes Involving Reductive Electron Transfer
}

\author{
Ludwig Chenneberg and Cyril Ollivier*
}

\begin{abstract}
Echoing the recent celebration of the fortieth anniversary of the Barton-McCombie reaction, this review aims to explore another facet of radical processes for deoxygenation of alcohols by considering SET (single electron transfer) reduction of carboxylic ester, thiocarbonate and thiocarbamate derivatives. Various protocols have been developed relying on the use of organic and organometallic SET reagents, electrochemical conditions, photoinduced electron transfer processes and visible-light photoredox catalysis. Applications to the synthesis of molecules of interest provide a glimpse into the scope of these different approaches.
\end{abstract}

Keywords: Alcohols · Deoxygenation · Electron transfer $\cdot$ Radicals $\cdot$ Reduction

\section{Introduction}

Radical chemistry has witnessed an explosive growth over the last three decades. Owing to their mildness and high compatibility with functional groups, radical reactions have been firmly established as reliable and versatile tools for organic synthesis. ${ }^{[1]}$ But the main drawback is associated with the overuse of tin mediators to propagate chain reactions. These reagents are known for being toxic and purification of reaction products is a non-trivial task. Thus, tin residues are often detected in traces eliminating any possibility of radical reactions being used in industry. As pointed out by J. Walton, [2] it is time to escape from 'the tyranny of tin' and to devise valuable alternatives for the generation of radicals. One option consists in using stannane derivatives in a catalytic fashion or as supported reagents. ${ }^{[3]}$ Another has dealt with the development of tin-free mediators based for instance on silanes, phos-

\footnotetext{
${ }^{*}$ Correspondence: Dr. C. Ollivier

Institut Parisien de Chimie Moléculaire (UMR CNRS 8232)

UPMC Univ-Paris 06, Sorbonne Universités

4 Place Jussieu, C. 229, 75005 Paris, France

E-mail:cyril.ollivier@upmc.fr
}

phorus derivatives and less toxic metals. ${ }^{[1]}$ Interesting perspectives have opened up with the use of organoboranes ${ }^{[4]}$ and compounds responsible for electron-transfer reactions have been increasingly seen as valuable alternatives to tin radical chemistry. [5] However, mild and sustainable preparative redox processes limiting the utilization of substoichiometric amounts of metal complexes are still needed. Recently, visible-light photoredox catalysis has emerged as a valuable and efficient tool for the generation of radicals by single electron transfer (SET) reactions from an appropriate photocatalyst that absorbs light in the visible region. These conditions have demonstrated their high synthetic potential in various organic redox processes for fine chemical synthesis and contributed at the same time to the development of a greener radical chemistry. ${ }^{[6]}$

Among the mainstream transformations present in the synthetic toolbox of organic chemists, reduction of alcohols to alkanes has gained a place of choice. Hydroxyl functional groups can indeed participate in the construction of elaborated molecular structures and be removed in due course. However, the hydroxide anion is known as a poor leaving group, homolytic scission of non-activated carbon-hydroxyl bonds is not thermodynamically feasible and direct electron transfer reduction of alcohols requires very low negative potentials. A proposed solution was to convert the hydroxyl group to a good leaving group or to a suitable radical precursor. Yet, limitations of deoxygenation by ionic processes were encountered with sterically hindered and/or non-activated secondary and tertiary alcohols. ${ }^{[7]}$ In 2015 , the radical community celebrated the 40th anniversary of the discovery of the BartonMcCombie deoxygenation reaction, unanimously considered as the most common and important process to perform such a transformation. ${ }^{[8]}$ Originally, this approach was based first on the activation of a secondary or tertiary alcohol as a thiocarbonate or thiocarbamate precursor including the well-known xanthate followed by its subsequent reduction to alkane through a $n \mathrm{Bu}_{3} \mathrm{SnH} / \mathrm{AIBN}$ (cat)-mediated radical chain process under thermal conditions (Scheme 1, Eqn. 1). Several improvements have been achieved by replacing the tin mediator with silicon hydrides, ${ }^{[3,9]}$ cyclohexadienyl compounds, ${ }^{[10]}$ phosphorous reagents, ${ }^{[11]}$ organoboranes ${ }^{[4,12]}$ or DLP/ isopropanol.[13] In parallel, a great deal of effort has been devoted to the development of single electron transfer (SET) processes whose major advances will be highlighted in this brief review and will complement a former review published by Hartwig in 1983. ${ }^{[14]}$ Specific focus will be placed on reduction of alcohols to alkanes with emphasis on Barton-McCombie-type deoxygenations of alcohol derivatives involving SET reduction of carbonyl and thiocarbonyl-based functional groups. For that purpose, different methods using organic and organometallic SET reagents, electrochemical conditions and photoinduced electron transfer (PET) processes under UV light irradiation or by visiblelight photoredox catalysis will be presented (Scheme 1, Eqn. 2). Applications to the synthesis of molecules of interest such as natural products will also be discussed. 


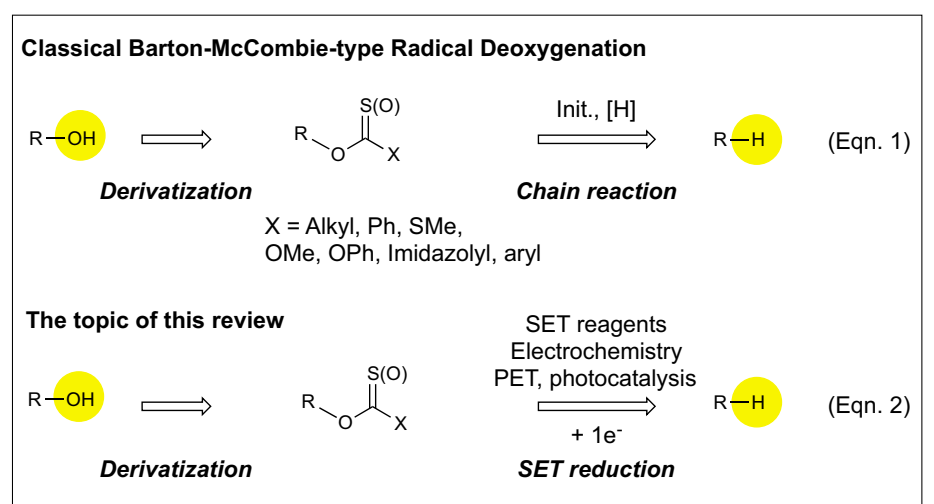

Scheme 1. SET reduction of carbonyl and thiocarbonylbased functional groups: Tin-free alternatives to the classical Barton-McCombie deoxygenation reaction of alcohols to alkanes.

\section{Metal-promoted Deoxygenation}

Low-valent metals such as alkali metals behave as good electron donors towards organic compounds. Owing to their high negative potential, these have been widely exploited in organic synthesis for electron transfer reduction of a range of functional groups including carbonyl moieties. The earliest observations date back to the beginning of the nineteenth century with successively the so-called Bouveault-Blanc reduction of carboxylic esters to alcohols by excess of sodium in ethanol (or amyl alcohol) ${ }^{[15]}$ and their bimolecular reductive coupling in refluxing aprotic solvents, better known as acyloin condensation. ${ }^{[16]}$ Both involved formation of a common ketyl-like radical anion intermediate subsesome other unexpected reactivities have been observed. In the nineteen-sixties, two different groups reported independently the uncanny ability of allylic-[17] and $\beta$-keto acetates ${ }^{[18]}$ to be reduced to alkanes by dissolving metals ( $\mathrm{Li}$ or $\mathrm{Ca}$ ) in liquid ammonia). Later, Stetter and Lehmann examined the behavior of allyl and benzyl benzoates upon reductive treatment with sodium. In this case, the transient radical anion of benzoates was assumed to undergo a $\beta$-fragmentation and expel an allyl or benzyl radical which should dimerize. ${ }^{[19]}$ al. designed a selective method of deoxygenation of sterically hindered secondary and tertiary alcohols to alkanes relying on the reduction of the corresponding acetates by alkali metals dissolved in amines. Two protocols involving either lithium in diethylamine or potassium solubilized by 18-crown-6 ether in tert-butylamine have been established and, applied for instance to the chemoselective cleavage of $6 \beta$ and $12 \alpha$ acetates in $3 \beta, 6 \beta$-diacetoxy-5 $\alpha$ cholestane and $3 \beta, 12 \alpha$-diacetoxy-13 $\alpha$ oleanane respectively. Conversely, less hindered acetates such as those at the $3 \beta$ position are more likely to regenerate the original hydroxyl groups. It means that the degree of selectivity is strongly related to the difference of steric environments quent to electron transfer. Over the years,

Along the same lines, Boar, Barton et
(Scheme 2, Eqn. 1). ${ }^{[20]}$ This methodology was applied to the synthesis of various natural products such as (-)-trichodiene ${ }^{[21]}$ using the $\mathrm{Li} / \mathrm{EtNH}_{2}$ system (Scheme 2, Eqn. 2), (-)-cladiella-6,11-dien-3-ol and its derivatives ${ }^{[22]}$ (Scheme 2, Eqn. 3) and ( \pm )-tormesol with $\mathrm{K} / 18-\mathrm{C}-6$ in $\mathrm{BBNH}_{2} /$ THF ${ }^{23]}$ (Scheme 2, Eqn. 4). A modified protocol with lithium $/ t$-BuOH in liquid ammonia was used by Mander et al. in the synthesis of C20 gibberellins. [24]

Further optimization of the reaction conditions and mechanistic studies were undertaken by Barrett, Barton et al. ${ }^{[25]}$ They particularly showed that increasing the bulk of the acyl substituent from methyl to isopropyl, to tert-butyl and to adamantyl enhances the yield in deoxygenation products (Scheme 2, Eqn. 1). Running reactions in tert-butylamine or 1,2-dimethoxyethane with THF as a co-solvent is more suitable than in a nucleophilic solvent such as diethylamine for impeding competitive amidolysis of acetates and regeneration of the starting alcohol. Moreover, deacylation may also be caused by the presence of 'adventitious' water and by crown ether-derived nucleophiles generated by degradation along the process. Thus, a new reduction system based on the use of a eutectic potassium/sodium alloy solubilized by aza 18-crown-6 1,4,7,10,13,16-hexamethyl1,4,7,10,13,16-hexaazacyclooctadecane in tert-butylamine/THF was developed and allowed the reduction of both hindered and non-hindered esters including primary esters. As examples, reduction of $5 \alpha$-cholestan-3 $\beta$-yl and octadecyl adamantane-1-carboxylates gave the products of deoxygenation in $90 \%$ and $74 \%$ yields respectively, but in the former case a Bouveault-Blanc reduction predominates at lower temperature (Scheme 3).

These experiments are fully consistent with a mechanism that involves one-

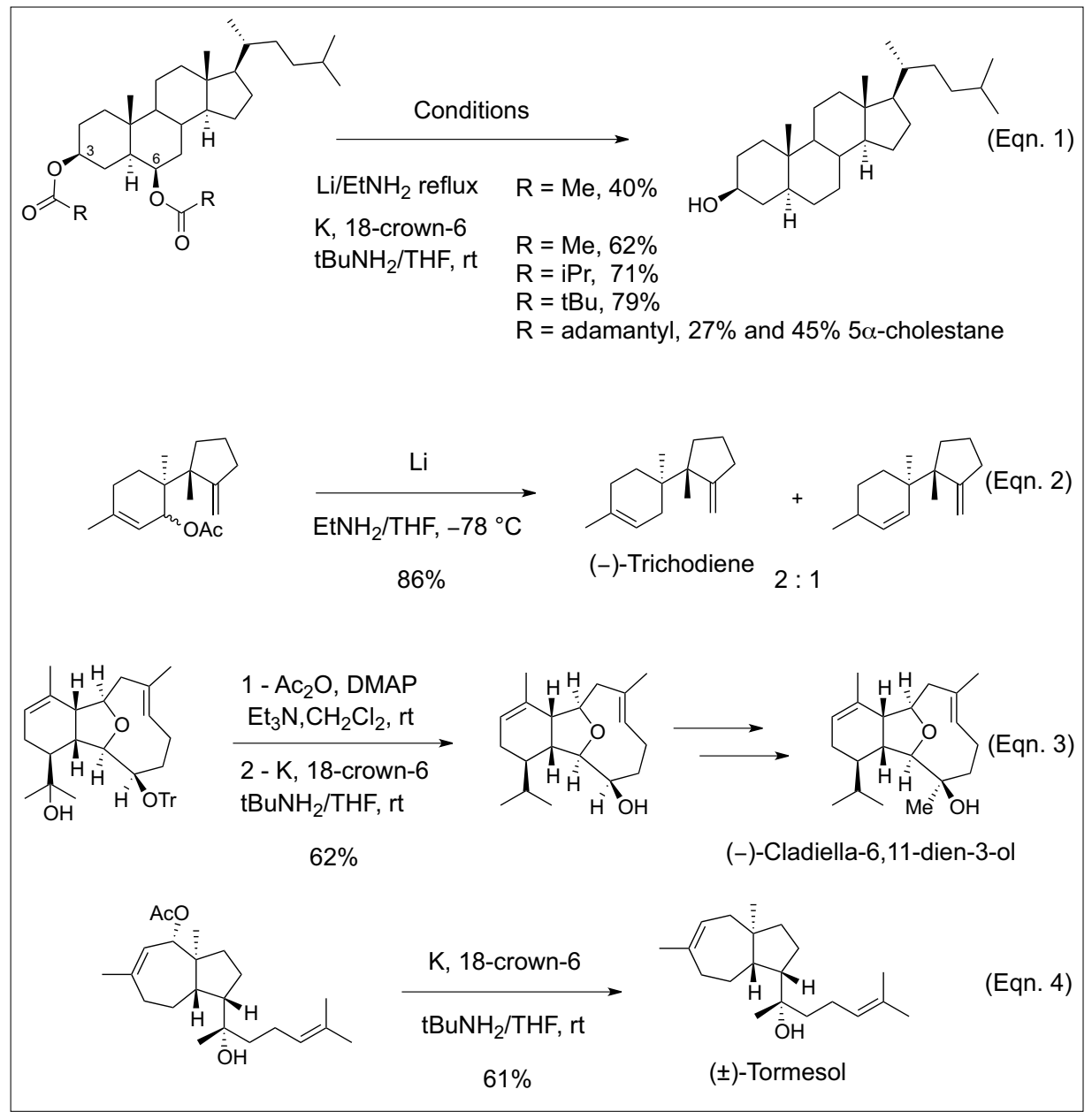

Scheme 2. Deoxygenation of sterically hindered secondary and tertiary alcohols by SET reduction of acetates with dissolved lithium and potassium. 


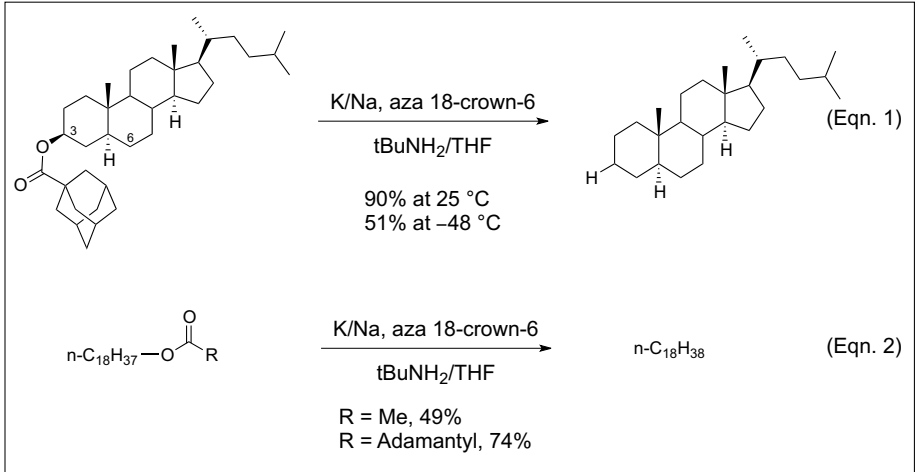

Scheme 3. Reduction of both hindered and non-hindered esters with eutectic potassium/sodium alloy solubilized by the aza 18-crown-6. genated products are isolated in good to moderate yields along with the starting alcohols (Scheme 6, Eqn. 1). ${ }^{[28]}$ Of particular importance is the presence of tert-butanol that ensures an optimal conversion in alkanes. Mechanistic investigations indicates the radical anion [HMPA $]^{-}$generated from HMPA and sodium and described by Normant et al.,[29] is capable of reducing the ester carbonyl and forming a classical ketyl-like radical-anion. Its fragmentation to a carbon-centered radical and a carboxylate anion turned out to be related to its electron transfer from dissolved metals to carboxylic ester, followed by formation of a ketyl-radical anion intermediate which fragments spontaneously leading to an alkyl radical and a carboxylate anion, an elementary step supported by ab initio calculations. ${ }^{[26]}$ Then, the expelled radical is in turn reduced to a carbanion and protonated subsequently to afford the alkane (Scheme 4). These conclusions are in accordance with previous studies reported by Pete $e t$ al. on photoreduction of acetate and benzoate esters to alkanes in hexamethylphosphoramide (HMPA) and water (vide infra).

In parallel, Barrett, Prokopiou and Barton presented an interesting extension of their previous works to the deoxygenation of non-hindered primary and secondary alcohols. They found that more stable precursors such as $N, N^{\prime}$-dialkylthiocarbamates, and precisely $N, N^{\prime}$-diethylthiocarbamates, can be reduced to alkanes with potassium solubilized by 18-crown-6 ether in tert-butylamine/THF (Scheme 5) whereas S-methyl dithiocarbonate and Nmonoalkylthiocarbamate compounds are precluded because the transformation becomes less effective. They also observed that low temperatures $\left(-30^{\circ} \mathrm{C}\right)$ have a detrimental effect on deoxygenation. Finally, a similar mechanism to that of carboxylic esters was considered. [27]

At the same time, inspired by their successful results on photoreduction of carboxylic esters by photoactivated HMPA (vide infra), Deshayes and Pete disclosed a more general but less selective protocol for the reduction of primary, secondary and tertiary carboxylic esters to alkanes which relies on the use of sodium in hexamethylphosphoramide (HMPA) as a reductive agent and tert-butanol as a proton source. As previously observed, the overall efficiency and selectivity of the deoxygenation process is highly dependent on the steric environment provided by the alcohol and the carboxylic acid residues. While homolytic scission of hindered tertiary esters to alkanes is almost quantitative in 5 min at room temperature, reductive cleavage of less hindered primary and secondary esters is partly achieved and the deoxy-

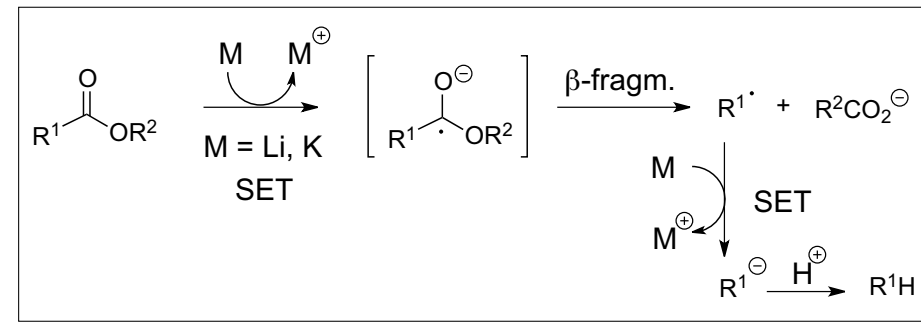

Scheme 4. A plausible mechanism for the reduction of carboxylic esters by dissolving metals.

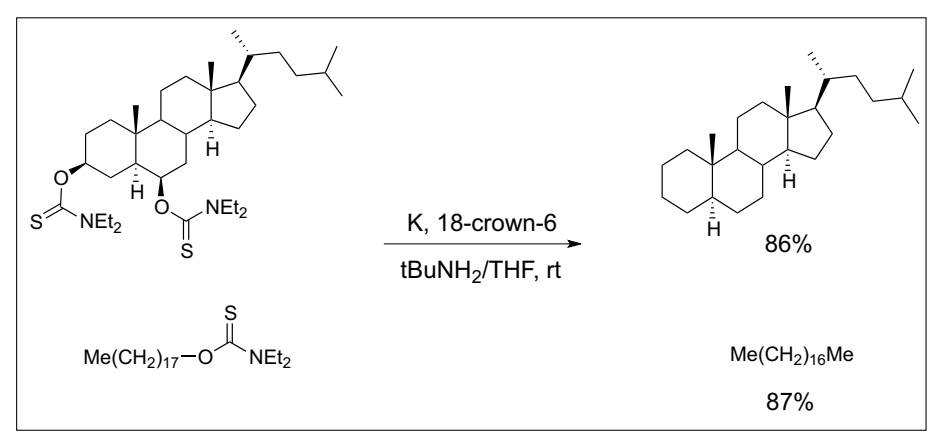

Scheme 5. Deoxygenation of nonhindered primary and secondary alcohols by SET reduction of $N, N$ '-diethylthiocarbamates with dissolved potassium.

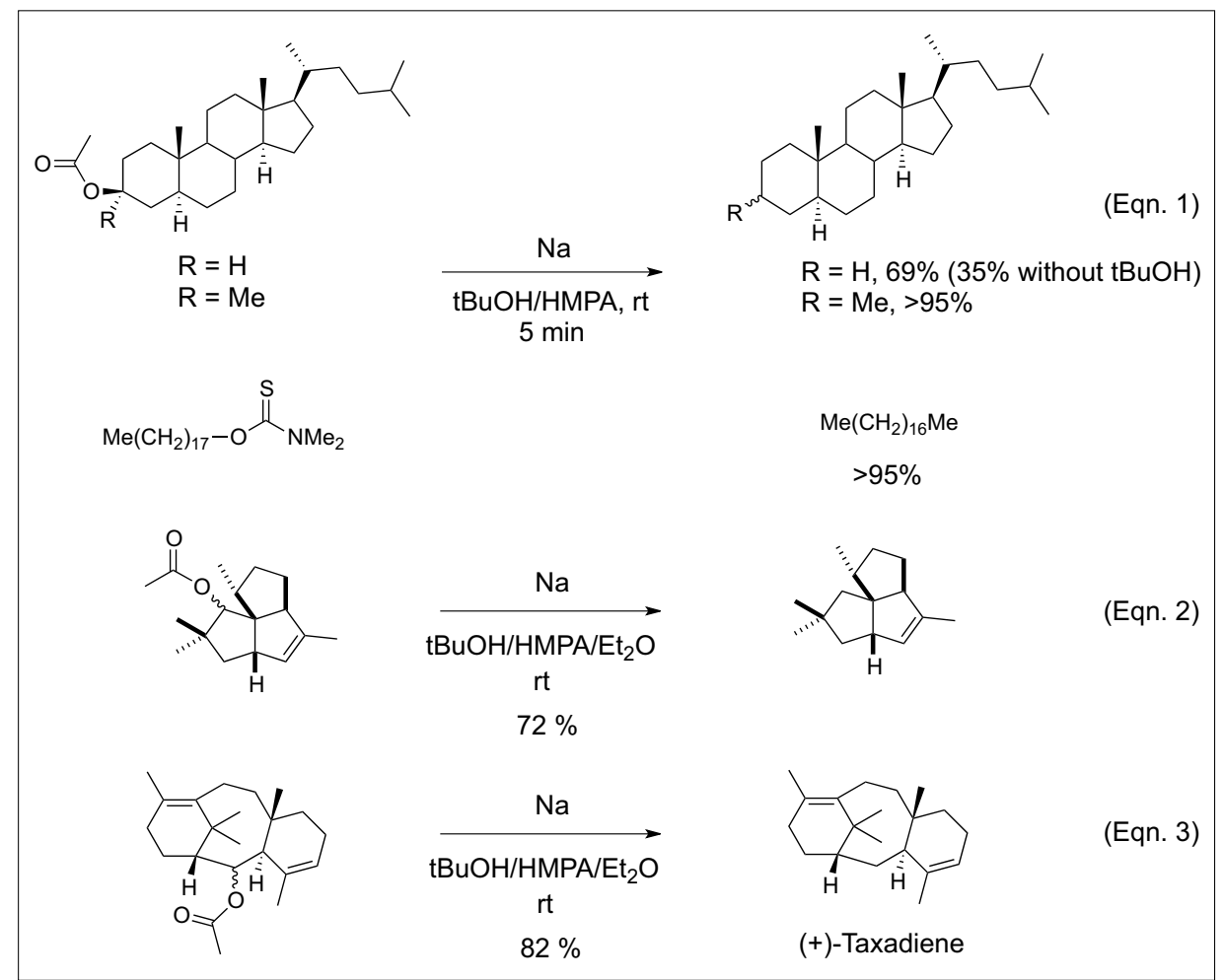

Scheme 6. Deoxygenation of primary, secondary and tertiary alcohols by reduction of acetates and $N, N^{\prime}$-dimethylthiocarbamates with sodium/HMPA. 
stability, the steric hindrance of both alkyl residues and the solvation of the anion moiety by tert-butanol which accelerates the homolytic scission. As confirmed by deuterium labeling experiments, the process ends up with the formation of the alkane mainly obtained by reduction of the generated radical to a carbanion and its subsequent protonation by tert-butanol, and a small amount by abstraction of a hydrogen atom to HMPA. To explain the presence of alcohol, hydrolysis, amidolysis and transesterification reactions of carboxylic esters have been suggested. ${ }^{[30]}$ Finally, extensive investigations have confirmed the great potential of thiocarbamates to participate in deoxygenation processes, as already observed in reduction studies with $\mathrm{K} / 18$ crown-6 ether (vide supra) and in photoreduction (vide infra). ${ }^{[31]}$ Starting from acetates or thiocarbamates, the method has found application in the synthesis of pentalenene (Scheme 6, Eqn. 2) ${ }^{[32]}$ and (+)-taxadiene (Scheme 6, Eqn. 3). ${ }^{\text {[33] }}$

Samarium(II) diiodide has been of paramount importance in the development of deoxygenation processes since in combination with HMPA it proved to be an efficient SET reagent for reduction of acetate and benzoate esters. In 1989, Inanaga et al. reported appropriate conditions for almost quantitative reduction of $\alpha$-acetoxy esters to saturated esters with the system $\mathrm{SmI}_{2} /$ HMPA in THF in the presence of $\mathrm{MeOH}$ (or EtOH) as a proton source in less than 5 min (Scheme 7, Eqn. 1). [34] Somewhat related is the reductive cleavage of acetate groups at the $\alpha$-position of $\gamma$ - and $\delta$-lactones (Scheme 7, Eqn. 2), which surprisingly does not require the use of HMPA, ${ }^{[35]}$ and at the anomeric position of ulosonic acid derivatives (Scheme 7, Eqn. 3). ${ }^{[36]}$ In the same vein, formation of carbon-carbon bonds can be realized by homolytic scission of an activated acetate or benzoate ester followed by SET reduction of the transient radical and subsequent addition of the generated alkylsamarium to a carbonyl compound. [37]

More recently, Markó et al. have extended the scope of this process to deoxygenation of non-activated primary, secondary and tertiary alkyl toluates by adding the substrate to a refluxing solution of $\mathrm{SmI}_{2} /$ HMPA in THF (or THP) and for a reaction time up to $5 \mathrm{~min}$. Intramolecular cyclizations have also been performed under these modified reductive conditions which proved compatible with alcohol, TBDMS ether, acetal, acetate and amide functional groups (Scheme 8). The mechanism is assumed to involve formation of a toluate radical anion by SET reduction followed by its fragmentation to a carboxylate and an alkyl radical. Then, the alkane is formed by hydrogen abstraction. The rate of decomposition is related to the stability of the

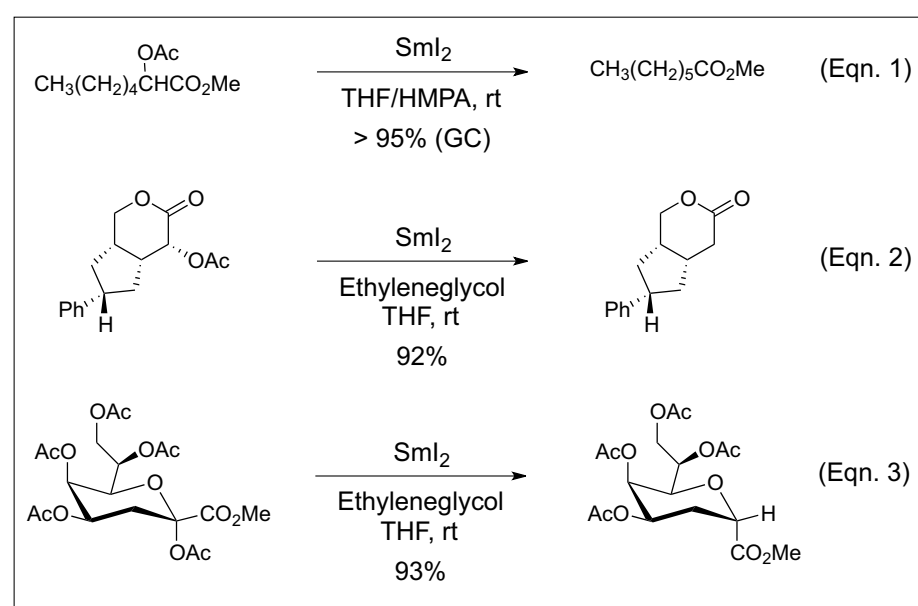

Scheme 7. Reduction of $\alpha$-acetoxy esters with samarium diiodide.

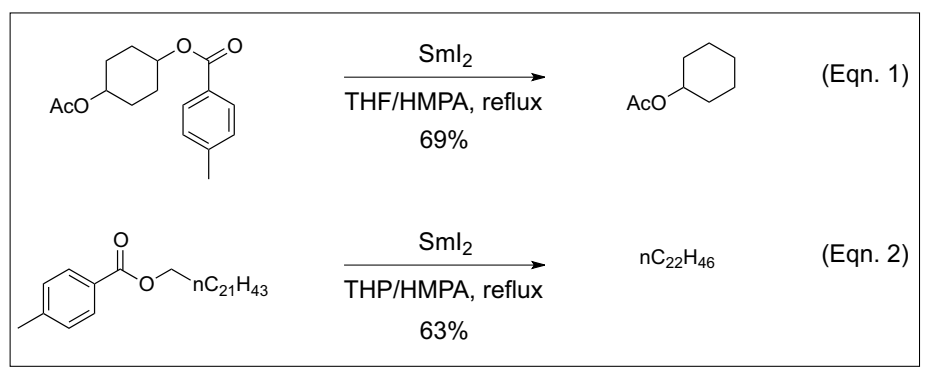

Scheme 8. Reduction of toluate esters with samarium diiodide.

intermediate which depends on the nature of the residue (allyl $>$ tertiary $>$ secondary $>$ primary) and the substitution of the aromatic (toluate $>$ benzoate). ${ }^{[38]}$

\section{Electrochemical Deoxygenation}

Electrochemical processes have proven to be some of the most economical and eco-friendly methods of achieving redox synthetic transformations since the unique source of electron is the current. ${ }^{[39]}$ In particular, electroreduction of organic halides and carbonyl compounds has been widely studied compared to the reductive cleavage of alcohols which required a high negative potential. To realize such deoxygenation processes, alcohols have been converted into acetates, oxalates or toluates prior to being electrochemically reduced.

Early research studies on this subject began in 1960 with the polarographic reduction of 2-acetoxyacetophenone to acetophenone by Henning Lund. ${ }^{[40]}$ Ten years after, Utley et al. were interested in the reductive electrolysis of para-methoxycarbonyl benzylacetate at a lead cathode in a methanol solution of tetra- $n$-butylammonium acetate as the supporting electrolyte. When a potential of $-1.8 \mathrm{~V} v s$. SCE is applied, the corresponding methyl para-toluate was obtained in $95 \%$ yield and with a good current efficiency. It is worthy of note that under these conditions, the cathodic reduction of acetoxyacetophenone is not chemoselective and leads to a mixture of acetophenone (20\%) and 1-phenylethanol (54\%), which results from the cleavage of the benzylic carbon-oxygen bond and the subsequent reduction of the carbonyl group. ${ }^{[41]}$ Logically, the behavior of allylic acetates was then examined. A preparative electrolysis of vitamin A acetate at a mercury pool cathode was performed in an acetonitrile solution of tetra- $n$-butylammonium acetate and acetic acid as a proton source at a controlled potential ( $-1.35 \mathrm{~V} v s$. Ag/AgI) and delivered axerophtene in $71 \%$ yield after the passage of $2 \mathrm{~F} / \mathrm{mol}$ of current. [42] Also, as shown by Tsujimoto et al., electrochemical reduction of 3-(2-naphthyl)2-butenyl acetate at a platinum cathode gave $(E)$-2-(2-naphthyl)-2-butene in 73\% yield. ${ }^{[43]}$ In 2002, Frontana-Uribe et al. explored the ability of the electrogenerated tetrabutylammonium-mercury amalgam to reduce aliphatic acetates. For instance, electroreduction of diosgenin acetate under a constant current ( $5 \mathrm{~mA}, 2.1 \mathrm{~F} / \mathrm{mol})$ gave rise to a $c a$. 1:1 ratio of alkane and alcohol, and the deoxygenated product could be isolated in $53 \%$ yield. These results are comparable with those obtained using alkaline metals and a similar mechanism involving a ketyl-like radical-anion formation and fragmentation can be proposed (vide supra). ${ }^{[4]}$

In that vein, oxalate esters exhibit a propensity to undergo reductive cleavage of the carbon-oxygen bond from alcohols at lower negative potentials ( $c a .-1.2 \mathrm{vs}$. $\mathrm{Ag} / \mathrm{AgI})$. Electron transfer from the cathode to oxalates was first highlighted by Voss with the formation of a stable semidione radical anion intermediate, evidenced by EPR experiments. This reduction turned out to be reversible for diethyl oxalate and irreversible for diallyl and 
dibenzyl oxalates in aprotic solution. ${ }^{[45]}$ Utley et al. suggested this irreversibility comes from a rapid fragmentation of the radical anion, as already observed with acetate (vide supra), which can be accelerated in protic conditions. Studies on benzyl oxalates supported a mechanism whereby transient radical anions collapse to benzyl radicals and oxalate anions and not the reverse. However, the process was hampered by competing hydrolysis of preformed oxalates, particularly of benzylic alcohols. The solution was found by generating in situ the reactive oxalate prior to be reduced via a co-electrolysis between benzylic (or allylic) alcohols and diethyl oxalate. For instance, reduction of diphenylmethanol under these conditions (mercury cathode, DMF-Bu $\mathrm{NClO}_{4},-1.6 \mathrm{~V}$ vs. Ag/AgI, $1 \mathrm{~F} /$ mol) gave diphenylmethane in $70 \%$ yield. Of interest, controlled potential electrolysis of oxalate of vicinal diols gave rise to olefinic adducts. ${ }^{[46]}$

As reported by Markó et al., aromatic esters such as toluates can also be regarded as valuable substrates for electrochemical deoxygenation of alcohols. A series was electrolyzed at $130{ }^{\circ} \mathrm{C}$ in a H-type cell equipped with a carbon graphic cathode and filled with tetrabutylammonium tetrafluoroborate and $N$-methylpyrrolidone (NMP) under a constant current (15 $\left.\mathrm{mA} . \mathrm{cm}^{-2}\right)$. Secondary and tertiary toluate esters were efficiently reduced to the desired alkanes and addition of a protic cosolvent such as isopropanol improved the yields. These conditions were found to be tolerant to a number of functional groups, including alkyl esters, amides, silyl ethers, ketones and free-alcohols (Scheme 9, Eqn. 1). ${ }^{[38 b, 47]}$ In contrast, primary toluates gave only moderate yields but by analogy with oxalates, a co-electrolysis between primary alcohols and methyl toluate provided an effective solution to that issue (Scheme 9, Eqn. 2). ${ }^{[48]}$

\section{Electron Transfer Deoxygenation from Carbon Dioxide Radical Anion}

The chemical system $\left(\mathrm{Bu}_{4} \mathrm{~N}\right)_{2} \mathrm{~S}_{2} \mathrm{O}_{8} /$ $\mathrm{HCO}_{2} \mathrm{Na}$ has aroused keen interest for its ability to generate carbon dioxide radical anion $\mathrm{CO}_{2}{ }^{--}$by oxidation with sulfate radical anion $\mathrm{SO}_{4}{ }^{--}$and then promote oneelectron reductive processes. In 1991, Hu and Qing took advantage of this reactivity to carry out per(poly)fluoroalkylation of olefins by reduction of per(poly)fluoroalkyl chlorides. ${ }^{[49]}$ Based on this seminal work, Kim et al. developed a new method for the radical deoxygenation of alcohols from thiocarbonyl derivatives. Using a mixture of $\left(\mathrm{Bu}_{4} \mathrm{~N}\right)_{2} \mathrm{~S}_{2} \mathrm{O}_{8}$ (3 equiv.)/ $\mathrm{HCO}_{2} \mathrm{Na}$ (6 equiv.) $/ \mathrm{Na}_{2} \mathrm{CO}_{3}$ (8 equiv.) in $\mathrm{DMF}$ at $50{ }^{\circ} \mathrm{C}$, good to excellent yields in

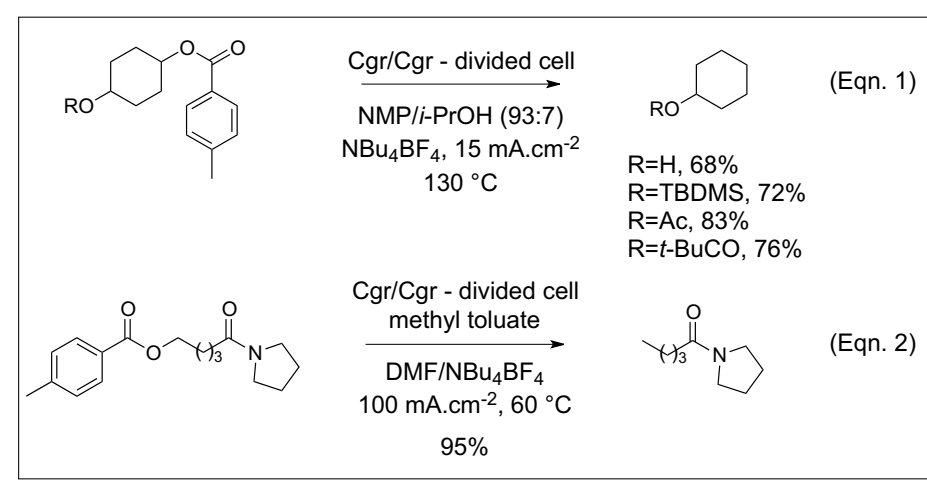

Scheme 9. Electrochemical reduction of toluate esters.

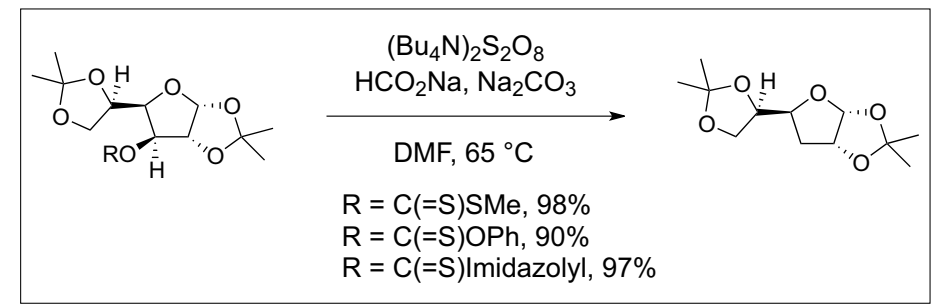

Scheme 10. Deoxygenation by reduction of thiocarbonyl derivatives with carbon dioxide radical anion.

alkane (up to $98 \%$ ) were reached whatever the nature of the radical precursor (xanthate, phenyl thionocarbonate or (thiocarbonyl) imidazolide) and the functional groups present in the substrate (Scheme 10). A SET mechanism was proposed involving electron transfer from carbon dioxide radical anion $\mathrm{CO}_{2}^{-}$to the thiocarbonyl function and $\beta$-scission of the tetrahedral radical anion intermediate. Deuterium labeling experiments then indicated that the expelled radical can abstract a hydrogen atom from the formate anion, the tetrabutylammonium cation and DMF to form the deoxygenated product. ${ }^{[50]}$ This transformation has been applied to the synthesis of platencin ${ }^{[51]}$ and a 3-des-hydroxyl analogue of (-)-clausenamide. ${ }^{[52]}$

\section{Photoinduced-Electron Transfer Deoxygenation}

Single electron transfer (SET) processes involving donor and acceptor organic molecules upon ultra-violet (UV) light irradiation have received a great deal of attention over the past decades ${ }^{[53]}$ while recent years have seen renewed interest for visible-light electron transfer photoredox catalysis. ${ }^{[6]}$ The potential of these photoinduced electron transfer phenomena have been widely exploited in organic synthesis. In particular, C-O homolytic cleavage of alcohols was successfully obtained by indirect reduction of carboxylic ester, thiocarbonate and thiocarbamate derivatives using photoactivated organic donors

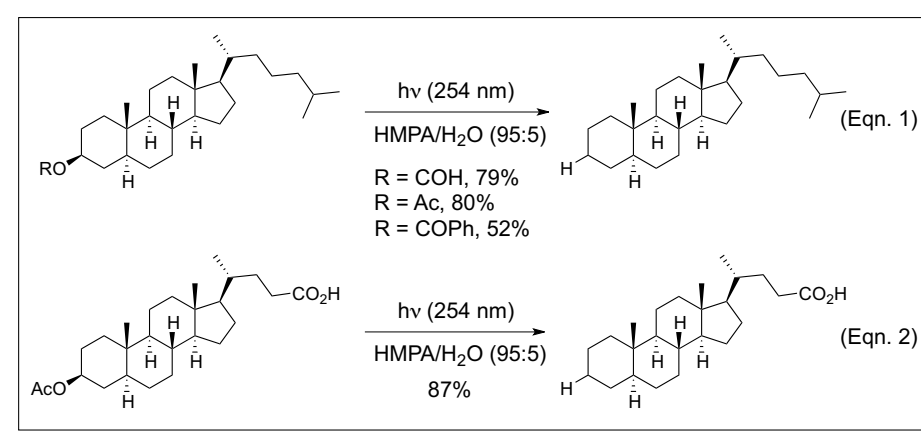

Scheme 11. Photoinduced electron transfer reduction of steroid carboxylic esters by $\mathrm{HMPA} / \mathrm{H}_{2} \mathrm{O}$ under UV irradiation.

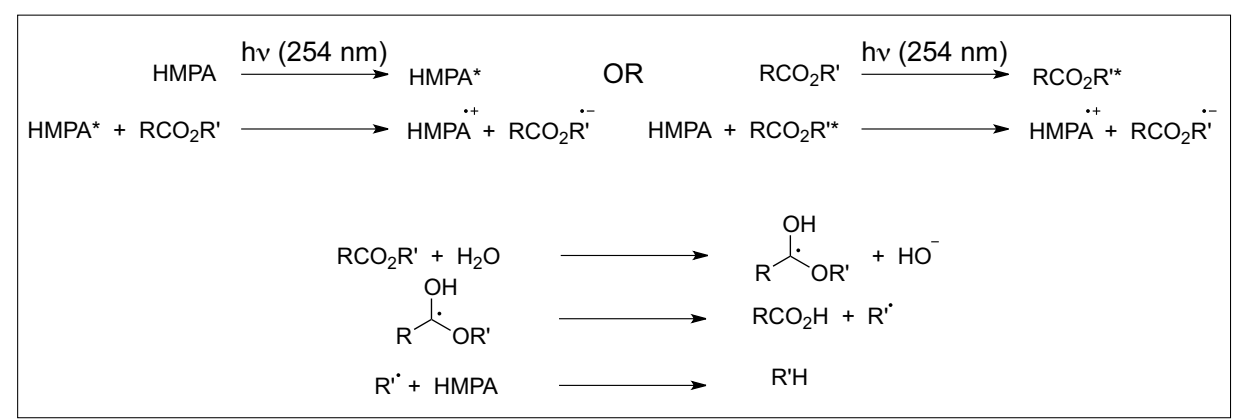

Scheme 12. A plausible mechanism for the photoreduction of carboxylic esters. 
such as hexamethylphosphoramide (HMPA), carbazoles and polypyridyl organometallic complexes of ruthenium(II) and iridium(III) as photocatalysts under UVvisible light conditions.

\subsection{UV Light-Induced Photodeoxy- genation Reactions}

Pioneering works on photodeoxygenation of benzoate or acetate esters in dry HMPA with a high-pressure mercury lamp were reported in the late 1960s by Beugelmans et al., who mentioned the presence of alkane side products ( $\mathrm{ca}$. 5\% yield after 30 h). ${ }^{[54]}$ In 1975 , Pete et al. optimized the reaction conditions by adding $5 \%$ of water to HMPA and irradiating with lowpressure mercury lamps (254 nm). Photoreduction of formate, acetate and benzoate esters gave the corresponding alkanes in moderate to good yields after 3 to $5 \mathrm{~h}$ of irradiation (Scheme 11, Eqn. 1). Primary, secondary, tertiary and neopentyl acetates could be smoothly converted into alkanes in short reaction times. While these conditions are compatible with a variety of functional groups including non-activated alkene, amide, acid, alcohol, ether and acetal (Scheme 11, Eqn. 2), limitations were encountered with activated alkenes, ketones and halides which are reduced at the same time and perfluorocarboxylic esters gave rise preferentially to $\alpha$-elimination of a fluorine atom. ${ }^{[55]}$ The presence of other chromophores in the starting material that absorbs UV radiation may also complicate the course of the reaction. ${ }^{56]}$

A detailed mechanistic study reported by Pete $e t$ al. suggests that the reaction proceeds through an electron transfer process from excited HMPA to the carboxylic ester as depicted in Scheme 12. Irradiation of the reaction mixture at $254 \mathrm{~nm}$ preferentially activates HMPA rather than esters - except with benzoates - and subsequent ester/HMPA* - or ester*/HMPA exciplex formation promotes reduction of the ester leading to a radical-ion pair. In the presence of water, the radical anion $\mathrm{RCO}_{2} \mathrm{R}$ '- was assumed to be trapped by protonation of the alcoholate preventing a reversal electron transfer and a regeneration of the starting materials. The latter tetrahedral radical intermediate can undergo a $\beta$-fragmentation and release an alkyl radical which can abstract a hydrogen atom to the HMPA and furnish the deoxygenated product. ${ }^{[57]}$ Further investigations based on laser flash photolysis of $\mathrm{HMPA} / \mathrm{H}_{2} \mathrm{O}$ solutions and quenching experiments support a mechanism involving photoionization of HMPA and reduction of carboxylic esters to transient radical anions by solvated electrons. To summarize, deuterium labeling experiments with HMPA- $\mathrm{d}_{18}$ and $\mathrm{D}_{2} \mathrm{O}$ reveal that hydrogen abstraction takes place

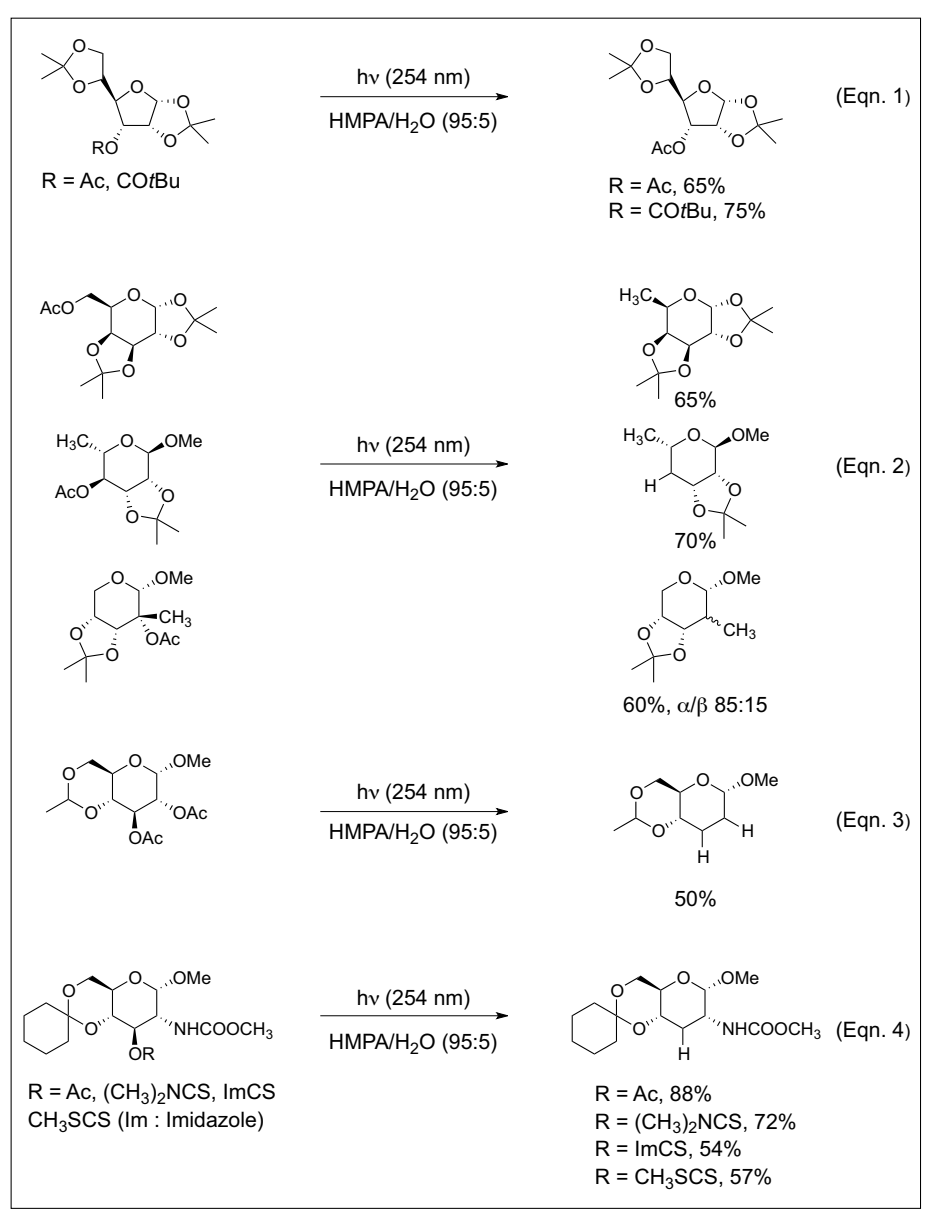

Scheme 13

Applications of the synthesis of deoxysugars from carbohydrate and aminoglucoside esters. preferentially at HMPA but also at the acid residue and the products. ${ }^{[58]}$

The versatility of this methodology was illustrated by the synthesis of deoxysugars from carbohydrate ${ }^{[59]}$ and amino-glucoside esters. ${ }^{[60]}$ Primary, secondary and even sterically hindered tertiary acetates or pivalates (Scheme 13, Eqn. 1 and Eqn. 2) as well as 1,2 diacetates (Scheme 13, Eqn. 3), 2 or 3,6 dipivalates attached on pyranose and furanose rings could be easily reduced to the corresponding alkanes. It is worthy of note that thiocarbamates ${ }^{[31 a, 61]}$ and dithiocarbonates, ${ }^{[62]}$ were also revealed as excellent precursors (Scheme 13, Eqn. 4). This deoxygenation procedure has found applications in the synthesis of advanced intermediates for 2,1-dehydro-5-homoadamantanone, ${ }^{663]}( \pm)$-trichodermol, ${ }^{[64]}$ and (+)-thienamycin. ${ }^{[65]}$

As valuable alternatives to the use of toxic HMPA, N-methylcarbazoles proved to be quite efficient and selective electron donor photosensitizers for the photoreduction of benzoate esters, especially when other chromophores are present in the substrates. In 1986, Saito et al. found success with the development of a general procedure for deoxygenation of secondary alcohols taking advantage of this photochemical property. The transformation relies on a photoinduced electron transfer process

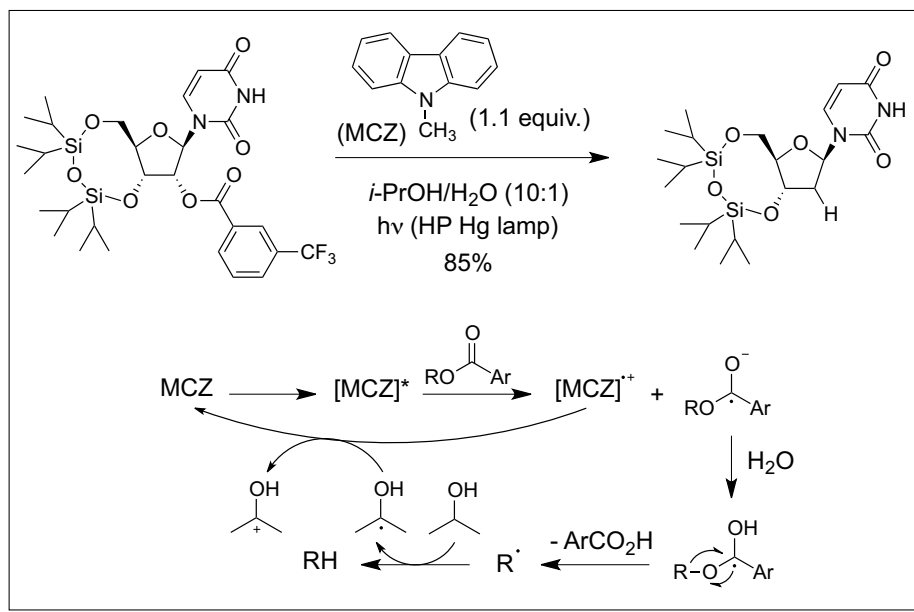

Scheme 14. The Saito photochemical reduction of a $m$ (trifluoromethyl)benzoate ester and the plausible mechanism. 
from the excited state of 9-methylcarbazole (MCZ) obtained by irradiation with a $400 \mathrm{~W}$ high-pressure mercury lamp to a simple benzoate or a $m$-(trifluoromethyl) benzoate ester derived from the alcohol in a mixture THF/water or isopropyl alcohol/ water (10:1) under nitrogen atmosphere at room temperature (Scheme 14). Of particular note, addition of magnesium perchlorate can speed up the photoreductive process. A similar mechanism to that obtained with HMPA was proposed. Reduction of the carboxylic ester by the photoactivated MCZ provides a transient radical anion which undergoes subsequent protonation with water and $\beta$-fragmentation. $\mathrm{H}$-abstraction from $i$-PrOH by the expelled radical was confirmed by deuterium labeling experiments. In theory, MCZ should be regenerated from the radical cation (MCZ) ${ }^{\circ+}$ by reduction with the solvent radical but in practice, at least one equivalent is required (Scheme 14). To explain, MCZ is irreversibly oxidized, as confirmed by cyclic voltammetry.[66]

Saito's process was then applied to various radical synthetic transformations. ${ }^{[67]}$ This powerful methodology provides entries to $\alpha$-deoxygenation of glucono, galactono and glucorono lactones derivatives, as illustrated by de Lederkremer and Marino. Surprisingly, in this case, the photoreduction was accomplished with only $10 \mathrm{~mol} \%$ of MCZ (Scheme 15, Eqn. 1).[68] Cyclopropylmethyl radical rearrangement for the formation of $\gamma, \delta$-unsaturated esters was achieved by Clive and Daigneault as depicted Scheme 15, Eqn. 2. ${ }^{[69]}$ In the course of the synthesis of isocarbacyclin, Noyori et al. demonstrated the utility of this methodology in the construction of the bicyclo[3.3.0]octane core structure obtained by generation of an $\alpha$-silylated radical from the corresponding alcohol and its subsequent 5-exo-dig cyclization (Scheme 15, Eqn. 3). ${ }^{[70]}$ In the same line, a radical cascade strategy implying transannular cyclizations in unsaturated macrocycles has been explored to elaborate 5-8-5 tricyclic ring systems. An elegant approach to the tobacco diterpenoid, 7,8-epoxy-4-basmen6-one, based on a 5-exo-trig/11-endo-trig radical cascade from an 14-membered cycloalkene-allenol was proposed by Myers and Condroski. The radical sequence was triggered by an secondary radical generated from the alcohol by using a modified Saito photochemical reduction protocol in the presence of 1,4-cyclohexadiene as a better source of hydrogen atom than the solvent (Scheme 15, Eqn. 4) .[71]

Inspired by the electrochemical studies of Ambrose et al. on 3- and 6-substituted 9-alkylcarbazoles, ${ }^{[72]}$ a catalytic version was developed by Rizzo et al., using 1020 mol\% of 3,6-dimethyl-9-ethylcarbazole (DMECZ) under the same conditions.

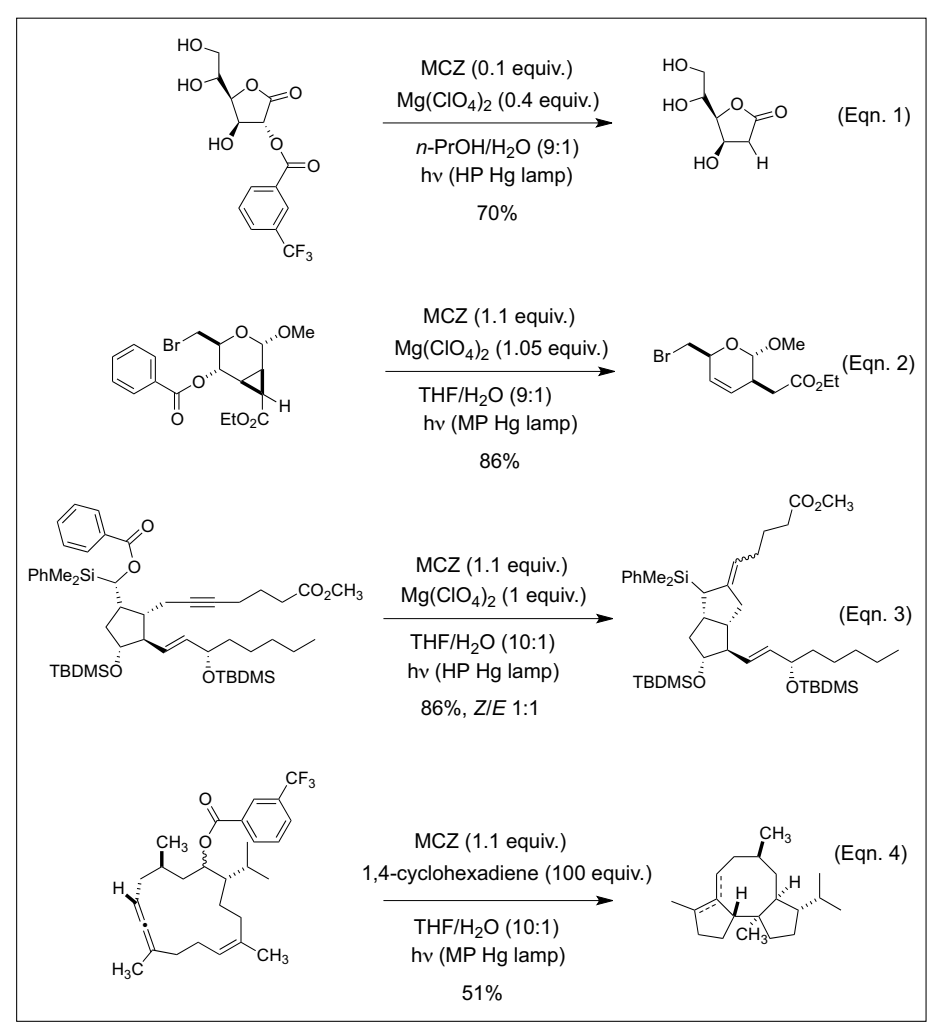

Scheme 15

Applications of the Saito's process to various radical synthetic transformations.

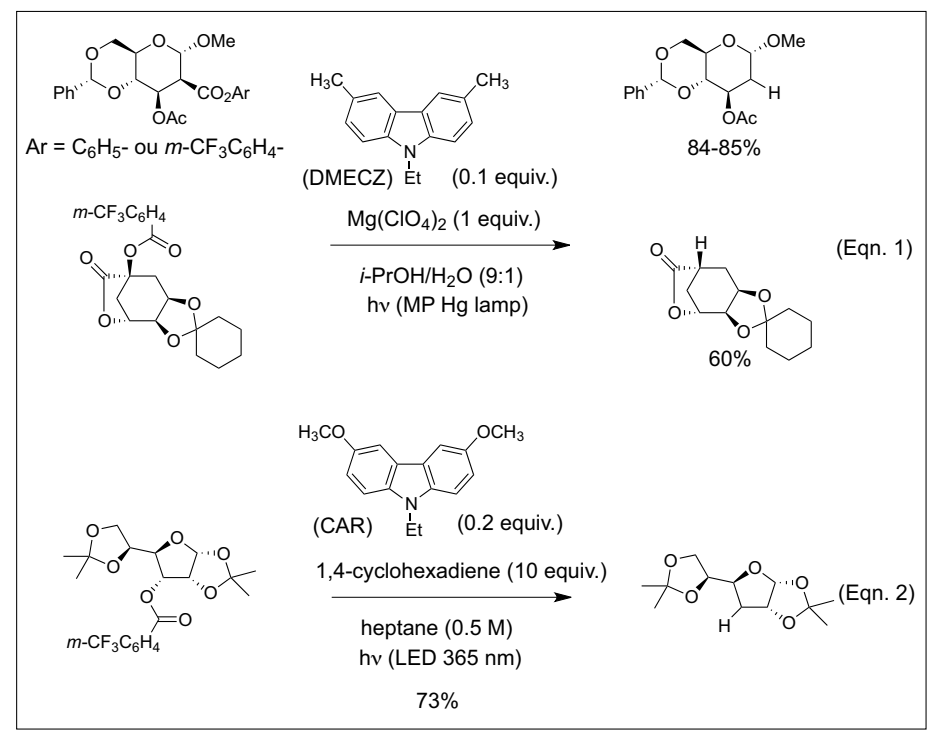

Scheme 16. The Saito photoreductive deoxygenation of benzoate esters under modified conditions with 3,6-disubstituted-9-ethylcarbazoles as new catalytic photosensitizers.

These variations significantly improved the turnover and the reactivity of the photosensitizer. In contrast to MCZ, DMECZ is reversibly oxidized during the process which ensures the regeneration of the photocatalyst. This modified protocol was tested to a series of substrates and proved to be compatible with alkene, ether, acetal, ester and lactone functions (Scheme 16, Eqn. 1).[73] Recently, the electron-rich 3,6-dimethoxy9-ethylcarbazole (CAR) has emerged as a more efficient photocatalyst increasing significantly the reaction rate. ${ }^{[74]}$ In addition, another study from Matsubara et al. showed that working at higher concentration (up to $0.5 \mathrm{M}$ ) avoids the formation of alkenes as side products. Finally, the best set of conditions relies on the use of 0.2 equiv. of CAR and 10 equiv. of 1,4-cyclohexadiene in heptane under LED $(365 \mathrm{~nm})$ irradiation (Scheme 16, Eqn. 2). ${ }^{[75]}$

The Saito photochemical reduction was then applied to the synthesis of relevant bioactive molecules including nonnatural 2'-deoxy-, 3'-deoxy- and 2',3'-dideoxyribonucleosides as potent anti-cancer drugs and antiviral compounds against AIDS. ${ }^{[76]}$ The strategy is based partly on the difference in reactivity between primary and secondary arylesters, benzoate and $m$-(trifluoromethyl)benzoate esters which can be reduced faster as illustrated Scheme 17. ${ }^{[76 b, c]}$ In continuous flow the reaction time to produce 2'-deoxyribonucleosides can be reduced from $2 \mathrm{~h}$ to $10 \mathrm{~min}$ when the reaction is carried out at 


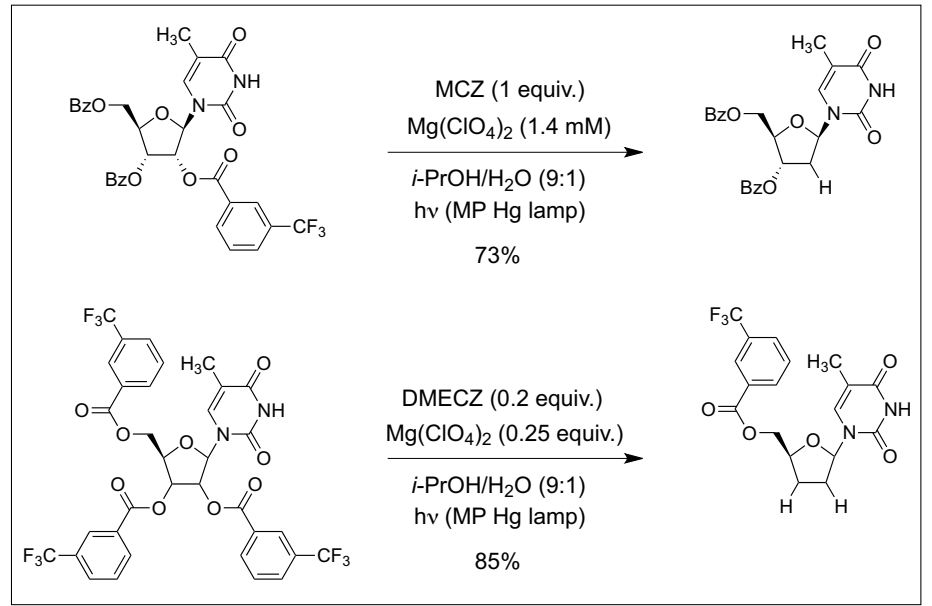

Scheme 17 Applications of the Saito's process to the synthesis of 2'-deoxyand 2',3'-dideoxyribonucleosides. presence of DIPEA. Then, the generated thiocarbamate radical anion fragments and affords the intermediate carbon-centered radical which can abstract an hydrogen to the amine radical cation (Scheme 18). ${ }^{[77]}$

Along the same line, Reiser et al. concentrated on deoxygenation of secondary benzylic, $\alpha$-carbonyl and $\alpha$-cyano alcohols. For that purpose, they revisited Saito's procedure under visible-light illumination. Starting from 3,5-bis(trifluoromethyl)benzoate esters, the reaction proceeds smoothly upon exposure to [Ir(ppy) ${ }_{2}$ (dtb-bpy)] $\mathrm{PF}_{6}$ catalysis in the presence of DIPEA and water in acetonitrile under LED lights at 40 $45^{\circ} \mathrm{C}$ with $10 \mathrm{~mol} \%$ of 3,6-dimethoxy-9ethylcarbazole. ${ }^{[74]}$ Finally, deoxygenation of aldonolactones was also accomplished through this methodology. ${ }^{[68]}$

\subsection{Visible Light-induced Photo- deoxygenation Reactions}

More appealing routes to perform photoreductive deoxygenations under milder conditions were recently reported with the rebirth of photoredox catalysis using visible light irradiation. ${ }^{[6]}$ These photoinduced SET processes require the presence of photocatalysts (Pcat) that absorb light in the visible range, which can be polypyridine transition metal complexes. Fensterbank, Goddard, Ollivier et al. have notably developed a photocatalytic alternative of the classical Barton-McCombie deoxygenation of aliphatic secondary and tertiary alcohols based on photoreduction of the corresponding imidazole $O$-thiocarbamates. Upon treatment with $f a c-\operatorname{Ir}(\mathrm{ppy})_{3}$ and diisopropylethylamine (DIPEA, Hünig's base) in acetonitrile under LED lights at room temperature, products of reduction were obtained in good to moderate yields (Scheme 18). Excellent functional group compatibility was observed with sulfonamide and tert-butoxycarbonyl protecting groups, aromatics, alkenes, acetals, alkyl esters, and lactones. By comparison, this transformation performed under standard tin hydride conditions gave the same results. However, photoreduction of the benzhydrol derivative furnished a mixture of 1,1-diphenylmethane (21\%) and dimer 1,1,2,2-tetraphenylethane $(37 \%)$. To gain insights into the mechanism, fluorescence quenching experiments and comparison of reduction potentials of a set of thiocarbamates $(-1.11$ to $-1.73 \mathrm{~V})$ with the $\operatorname{Ir}(\mathrm{IV}) /$ Ir(III)* redox system $(-1.73 \mathrm{~V})$ established that photoactivated $f a c$ - $\operatorname{Ir}(\mathrm{ppy})_{3}$ * reduces the $O$-thiocarbamates. This information allowed to propose a reasonable mechanism where $\mathrm{fac}$ - $\operatorname{Ir}(\mathrm{ppy})_{3}$ * can transfer an electron to the thiocarbamate moiety and the photocatalyst is regenerated in the
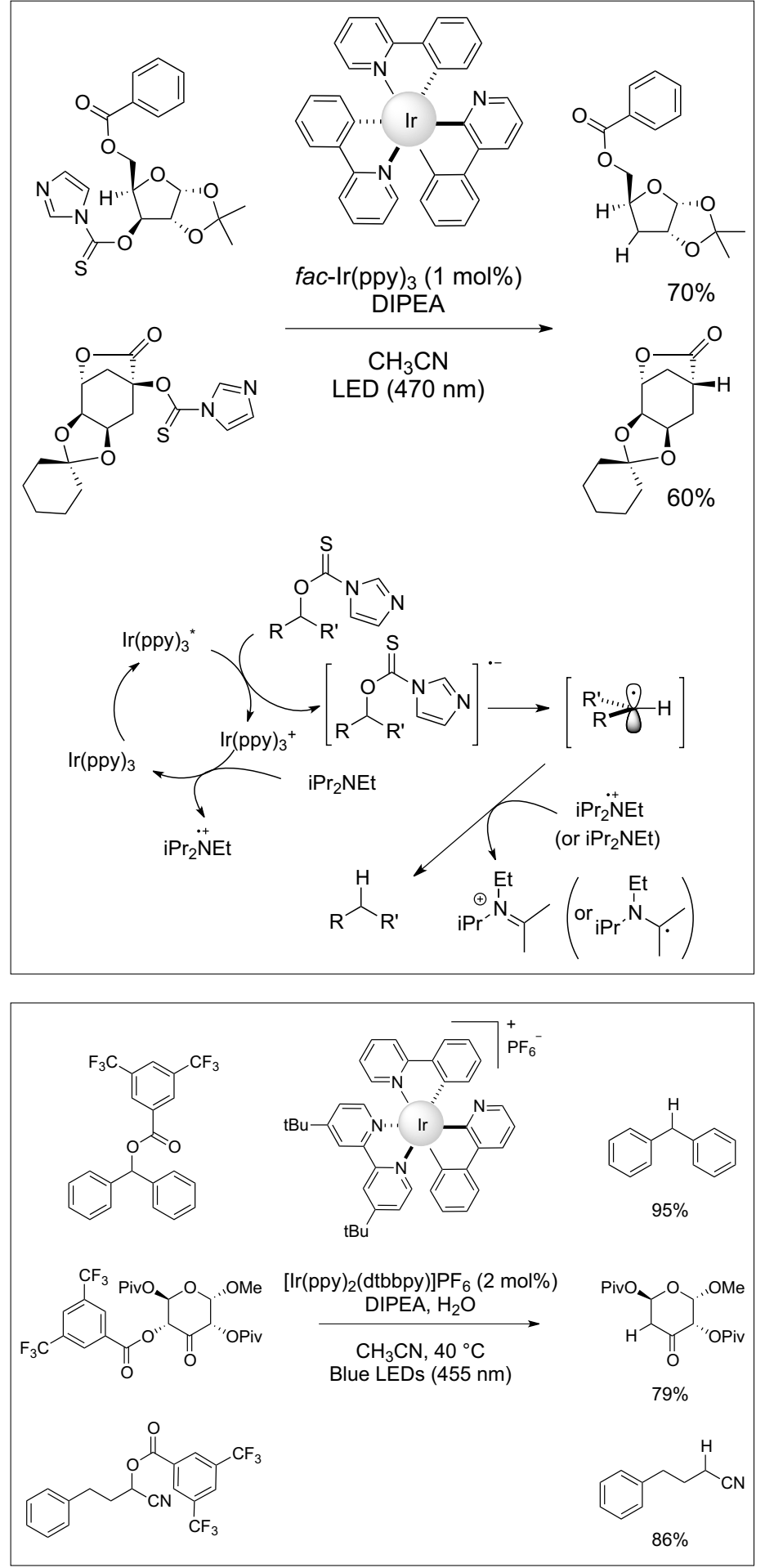

Scheme 18. Photocatalytic reduction of secondary and tertiary $\mathrm{O}$-thiocarbonates and the plausible mechanism.

Scheme 19 Photocatalytic reduction of 3,5-bis(trifluoromethyl)benzoate esters. 


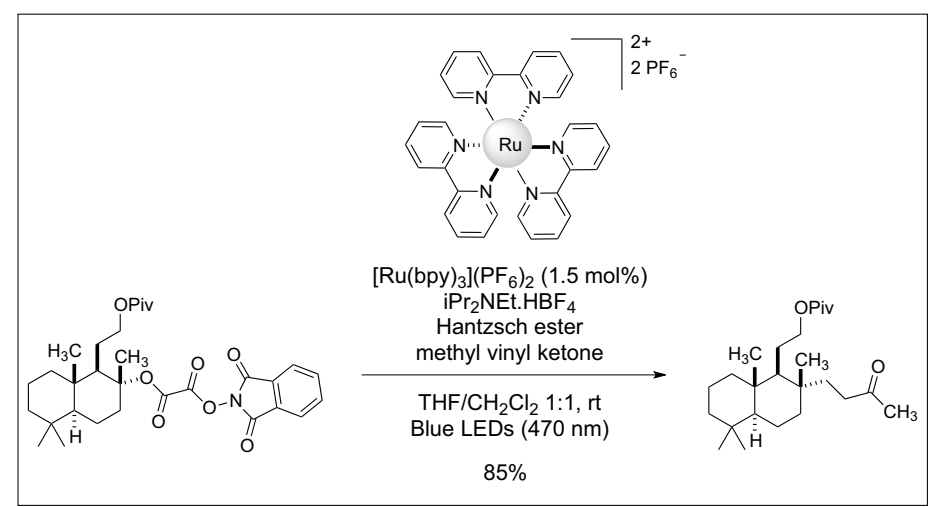

Scheme 20. Visiblelight photoreductive coupling of a tert-alkyl N-(acyloxy) phthalimide oxalate and methyl vinyl ketone.
${ }^{\circ} \mathrm{C}$. This catalytic system proved tolerant to a large number of functional groups. In contrast with $O$-thiocarbonates, no dimer was formed in photoreduction of benzhydrol derivatives (Scheme 19). As seen before, it is assumed that the iridium complex acts as a visible-light photocatalyst, DIPEA is required as both a sacrificial electron donor and a hydrogen atom donor, and water may be involved in the protonation of the transient radical anion $\mathrm{RCO}_{2} \mathrm{R}^{10}$. ${ }^{[78]}$

In 2012, Overman et al. made use of Okada's decarboxylation ${ }^{[79]}$ to provide an efficient method for the deoxygenation of aliphatic tertiary alcohols by photoreduction of the corresponding tert-alkyl $\mathrm{N}$-(acyloxy)phthalimide oxalates. The reaction relies on a combination of $\mathrm{Ru}(\mathrm{bpy})_{3}\left(\mathrm{PF}_{6}\right)_{2}$ photocatalyst (1.5 $\mathrm{mol} \%$ ) and visible-light (blue LEDs) with Hantzsch ester and $i$-Pr $\mathrm{NEt}_{2} \mathrm{HBF}_{4}$ which presumably serves as both a reductive quencher and $\mathrm{H}$-atom donor. After two successive decarboxylations, the tertiary alkyl radicals can then be trapped by electrondeficient alkenes leading to the formation of quaternary centers (Scheme 20). ${ }^{\text {[80] }}$

\section{Conclusion and Perspectives}

Since the pioneering work of D. H. R. Barton and S. W. McCombie on tin-mediated radical deoxygenation of alcohols from the corresponding xanthates, tremendous developments on tin-free alternative methods for synthesis have been widely reported. Among them, reductive single electron transfer (SET) approaches involving acetate, aromatic ester, dithiocarbonate and dithiocarbamate precursors prove to be extremely effective in the conversion of alcohols to alkanes, and particularly with sterically hindered substrates. This overview points out a variety of successful SET conditions including the use of low valent metal, such as dissolving alkali metals (Li, $\mathrm{Na}, \mathrm{K}$ ) and lanthanides (Sm(II)), and the chemical system $\left(\mathrm{Bu}_{4} \mathrm{~N}_{2} \mathrm{~S}_{2} \mathrm{O}_{8} / \mathrm{HCO}_{2} \mathrm{Na}\right.$ as a source of carbon dioxide radical anion, but also electrochemical and photoinduced electron transfer conditions which demon- strates their high synthetic potential. Finally, recent studies confirm the increasing importance of photoredox catalysis as a very attractive tin-free process and a valuable tool in modern organic synthesis for deoxygenation of alcohols, but is far from being completely exploited.

\section{Acknowledgements}

We thank UPMC and CNRS. L. C. was awarded a graduate fellowship by the Région Martinique and the LabEx MiChem, part of French state funds managed by the ANR within the Investissements d'Avenir programme under reference ANR-11-IDEX-0004-02, which are gratefully acknowledged. We are warmly thankful for the sponsorship of the COST Action CM1201 on Biomimetic Radical Chemistry.

Received: June 17, 2015

[1] For a comprehensive account on all aspects of radical chemistry, see: a) 'Radicals in Organic Synthesis', Eds. P. Renaud, M. P. Sibi, Wiley$\mathrm{VCH}$, Weinheim, 2001; b) 'Encyclopedia of Radicals in Chemistry, Biology and Materials', Eds. C. Chatgilialoglu, A. Studer, John Wiley \& Sons, Ltd, Chichester, UK, 2012.

[2] P. A. Baguley, J. C. Walton, Angew. Chem. Int. Ed. 1998, 37, 3072.

[3] A. Studer, S. Amrein, Synthesis 2002, 835

[4] a) C. Ollivier, P. Renaud, Chem. Rev. 2001, 101, 3415; b) P. Renaud, A. Beauseigneur, A. Brecht-Forster, B. Becattini, V. Darmency, S. Kandhasamy, F. Montermini, C. Ollivier, P. Panchaud, D. Pozzi, E. M. Scanlan, A.-P. Schaffner, V. Weber, Pure Appl. Chem. 2007, $79,223$.

[5] a) P. I. Dalko, Tetrahedron 1995, 51, 7579; b) U. Jahn in 'Top. Curr. Chem., Radicals in Organic Synthesis, Vol. 3', Eds. M. Heinrich, A. Gansäuer, Wiley-VCH, Weinheim, 2012, Vol. 320, p. 121, 191 and 323; c) A. Gansäuer, H. Bluhm, Chem. Rev. 2000, 100, 2771.

[6] For selected reviews, see: a) J. M. R Narayanaman, C. R. J. Stephenson, Chem. Soc. Rev. 2011, 40, 102; b) F. Teplý, Collect. Czech. Chem. Commun. 2011, 76, 859; c) J. Xuan, W.J. Xiao, Angew. Chem. Int. Ed. 2012, 51, 6828; d) M. A. Ischay, T. P. Yoon, Eur. J. Org. Chem. 2012, 3359; e) L. Shi, W. Xia, Chem. Soc. Rev. 2012, 41, 7687; f) C. K. Prier, D. A. Rankic, D. W. C. MacMillan, Chem. Rev. 2013, 113, 5322; g) D. P. Hari, B. König, Angew. Chem. Int. Ed. 2013, 52, 4734; h) M. Reckenthäler, A. G. Griesbeck, Adv. Synth. Catal. 2013, 355, 2727; i) T. Koike, M. Akita, Synlett 2013, 24 2492; j) J. Xuan, L.-Q. Lu, J.-R. Chen, W.-J.
Xiao, Eur. J. Org. Chem. 2013, 6755; k) J. Hu, J. Wang, T. H. Nguyen, N. Zheng, Beilstein J. Org. Chem. 2013, 9, 1977; 1) M. N. Hopkinson, B. Sahoo, J.-L. Li, F. Glorius, Chem. Eur. J. 2014, 20, 3874; m) D. M. Schultz, T. P. Yoon, Science 2014, 343, 985. For recent books, see: n) "Chemical Photocatalysis", Ed. B. König, DeGruyter, Berlin, 2013; o) 'Photochemically generated intermediates in Synthesis', Eds. A. Albini, M. Fagnoni, John Wiley \& Sons, Hoboken, 2013.

[7] a) S. W. McCombie, in 'Comprehensive Organic Synthesis', Eds. B. Trost, I. Fleming, Pergamon Press, New York, 1991, Vol. 8, p. 811; b) L. Chenneberg, J.-P. Goddard, L. Fensterbank, in 'Comprehensive Organic Synthesis (2nd Edition)', Eds. G. Molander, P. Knochel, Elsevier, Oxford, 2014, Vol. 8, p. 1011.

[8] a) D. H. R. Barton, S. W. McCombie, J. Chem. Soc., Perkin Trans. I 1975, 1574. For reviews, see: b) D. Crich, L. Quintero, Chem. Rev. 1989, 89,1413 ; c) S. W. McCombie, W. B. Motherwell, M. J. Tozer, Org. React. 2012, 77, 161.

[9] a) D. H. R. Barton, D. O. Jang, J. C. Jaszberenyi, Tetrahedron 1993, 49, 2793; b) D. H. R. Barton, D. O. Jang, J. C. Jaszberenyi, Tetrahedron 1993, 49, 7193; c) M. Oba, K. Nishiyama, Tetrahedron 1994, 50, 10193; d) D. O. Jang, J. Kim, D. H. Cho, C.-M. Chung, Tetrahedron Lett. 2001, 42, 1073; e) J. Kim, D. H. Cho, D. O. Jang, Tetrahedron Lett. 2004, 45, 3031; f) M. Oba, K. Nishiyama, Chem. Commun. 1994, 1703. For a review on the use of silanes, see: g) 'Organosilanes in Radical Chemistry', Ed. C. Chatgilialoglu, John Wiley \& Sons Ltd, Chichester, 2004

[10] Silylated-cyclohexadienyl compounds: A. Studer, S. Amrein, Angew. Chem. Int. Ed. 2000, 39, 3080.

[11] a) D. O. Jang, D. H. Cho, D. H. R. Barton, Synlett 1998, 39; b) A. E. Graham, A. V. Thomas, R. Yang, J. Org. Chem. 2000, 65, 2583; c) J. Boivin, R. Jrad, S. Juge, V. T. Nguyen, Org. Lett. 2003, 5, 1645.

12] Phosphine-borane complexes: a) D. H. R. Barton, M. Jacob, Tetrahedron Lett. 1998, 39, 1331; b) D. A. Spiegel, K. B. Wiberg, L. N. Schacherer, M. R. Medeiros, J. L. Wood, $J$. Am. Chem. Soc. 2005, 127, 12513; c) G. A. Nishiguchi, R. D. Little, J. Org. Chem. 2005, 70, 5249; d) M. K. Kreilein, J. E. Hofferberth, A. C. Hart, L. A. Paquette, J. Org. Chem. 2006, 71, 7329. NHC-borane complexes: e) S.-H. Ueng, M. Makhlouf-Brahmi, E. Derat, L. Fensterbank, E. Lacôte, M. Malacria, D. P. Curran, J. Am. Chem. Soc. 2008, 130, 10082; f) A. Solovyev, S-H. Ueng, J. Monot, L. Fensterbank, M. Malacria, E. Lacôte, D. P. Curran, Org. Lett. 2010, 12, 2998; g) S-H. Ueng, L. Fensterbank, E. Lacôte, M. Malacria, D. P. Curran, Org. Lett. $\mathbf{2 0 1 0}, 12,3002$. For a review on the use of NHCboranes, see: h) D. P. Curran, A. Solovyev, M. Makhlouf-Brahmi, L. Fensterbank, M. Malacria, E. Lacôte, Angew. Chem. Int. Ed. 2011, 50, 10294. For deoxygenation initiated by $\mathrm{Et}_{3} \mathrm{~B}$, see: i) J. Boivin, V. T. Nguyen, Beilstein J. Org. Chem. 2007, 3, 1; j) J. Boivin, V. T. Nguyen, Beilstein J. Org. Chem. 2007, 3, doi:10.1186/1860-5397-3-47; k) F. Allais, J. Boivin, V. T. Nguyen. Beilstein J. Org. Chem. 2007, 3, doi:10.1186/1860-5397-3-46.

[13] A. Liard, B. Quiclet-Sire, S. Z. Zard, Tetrahedron Lett. 1996, 37, 5877.

[14] W. Hartwig, Tetrahedron 1983, 39, 2609.

[15] a) L. Bouveault, G. Blanc, C. R. Acad Sci Paris 1903, 136, 1676; b) L. Bouveault, G. Blanc, $C$. R. Acad Sci Paris 1903, 137, 60 and 328; c) L. Bouveault, G. Blanc, Bull. Soc. Chim. Fr. 1903, 29, 787. d) L. Bouveault, G. Blanc, Bull. Soc. Chim. Fr. 1904, 31, 666, 1206 and 1213. 
[16] a) L. Bouveault, R. Locquin, C. R. Acad. Sci. Paris 1905, 140, 1593; b) L. Bouveault, R. Locquin, Bull. Soc. Chim. Fr. 1906, 35, 629; c) S. M. MeEIvain, Org. React. 1948, 4, 256; d) K. T. Finley, Chem. Rev. 1964, 64, 573; e) J. J. Bloomfield, D. C. Owslcy, C. Ainworth, R. E. Robertson, J. Org. Chem. 1975, 40, 393 .

[17] a) P. Bladon, H. B. Henbest, E. R. H. Jones, B. J. Lovell, G. F. Woods, J. Chem. Soc. 1954, 125. b) A. S. Hallsworth, H. B. Henbest, T. I. Wrigley, J. Chem. Soc. 1957, 1969.

[18] J. H. Chapman, J. Elks, G. H. Phillipps, L. J. Wyman, J. Chem. Soc. 1956, 4344.

[19] H. Stetter, K.-A. Lehmann, Liebigs Ann. Chem. 1973, 499.

[20] R. B. Boar, L. Joukhadar, J. F. McGhie, S. C. Misra, A. G. M. Barrett, D. H. R. Barton, P. A. Prokopiou, J. Chem. Soc., Chem. Commun. 1978, 68.

[21] J. C. Gilbert, R. D. Selliah, J. Org. Chem. 1993 58,6255 .

[22] a) H. Kim, H. Lee, J. Kim, S. Kim, D. Kim, J. Am. Chem. Soc. 2006, 128, 15851; b) J. S. Clark, R. Berger, S. T. Hayes, L. H. Thomas, A. J. Morrison, L. Gobbi, Angew. Chem. Int. Ed. 2010, 49, 9867.

[23] H. Kim, H. Bae, S. Kim, D. Kim, D. Lee, R. S. Paton, Tetrahedron 2011, 67, 10017.

[24] R. D. Dawe, L. N. Mander, J. V. Turner, P. Xinfu, Tetrahedron Lett. 1985, 26, 5725.

[25] a) A. G. M. Barrett, P. A. Prokopiou, D. H. R. Barton, R. B. Boar, J. F. McGhie, J. Chem. Soc., Chem. Commun. 1979, 1173; b) A. G. M. Barrett, C. R. A. Godfrey, D. M. Hollinshead, P. A. Prokopiou, D. H. R. Barton, R. B. Boar, L. Joukhadar, J. F. McGhie, S. C. Misra, J. Chem. Soc., Perkin Trans. 1 1981, 1501; c) D. H. R. Barton, W. B. Motherwell, Pure and Appl. Chem. 1981, 53, 1081 .

[26] P. Cremaschi, G. Morosi, M. Simonetta, Angew. Chem. Int. Ed. Engl. 1981, 20, 673

[27] A. G. M. Barrett, P. A. Prokopiou, D. H. R. Barton, J. Chem. Soc., Chem. Commun. 1979, 1175 .

[28] H. Deshayes, J.-P. Pete, J. Chem. Soc, Chem. Commun. 1978, 567.

[29] a) H. Normant, Bull. Soc. Chim. Soc. 1968, 791; b) H. Normant, Angew. Chem. Int. Ed. 1967, 6, 1046.

[30] H. Deshayes, J.-P. Pete, Can. J. Chem. 1984, 2063.

[31] a) Y. A. Dembélé, H. Deshayes, J.-P. Pete, Tetrahedron Lett. 1982, 23, 3489; b) A. Dembélé, H. Deshayes, J.-P. Pete, Bull. Soc. Chim. Fr. 1988, 671.

[32] L. A. Paquette, F. Geng, Org. Lett. 2002, 4, 4547.

[33] a) A. Mendoza, Y. Ishihara, P. S. Baran, Nature Chem. 2012, 4, 21; b) Y. Ishihara, A. Mendoza, P. S. Baran, Tetrahedron 2013, 69, 5685.

[34] K. Kusuda, J. Inanaga, M. Yamaguchi, Tetrahedron Lett. 1989, 30, 2945.

[35] a) J. Inanaga, J. Katsuki, M. Yamaguchi, Chem. Lett. 1991, 20, 1025. b) S. Hanessian, C. Girard, J. L. Chiara, Tetrahedron Lett. 1992, 33, 573.

[36] S. Hanessian, C. Girard, Synlett 1994, 863.
[37] a) E. J. Enholm, S. Jiang, Tetrahedron Lett. 1992, 33, 6069; b) E. J. Enholm, S. Jiang, K. Abboud, J. Org. Chem. 1993, 58, 4061; c) A. Malapelle, Z. Abdallah, G. Doisneau, J.-M. Beau, Angew. Chem. Int. Ed. 2006, 45, 6016.

[38] a) K. Lam, I. E. Markó, Org. Lett. 2008, 10, 2773; b) K. Lam, I. E. Markó, Tetrahedron 2009, 65, 10930 .

[39] 'Organic Electrochemistry, 4 4h $^{\text {th }}$ ed.', Eds. H. Lund, O. Hammerich, Marcel Dekker: New York, 2001.

[40] H. Lund, Acta Chem. Scand. 1960, 14, 1929.

[41] a) J. P. Coleman, H. G. Gilde, J. H. P. Utley, B. C. L. Weedon, J. Chem. Soc. D 1970, 738; b) J. P. Coleman, Naser-ud-din, H. G. Gilde, J. H. P. Utley, B. C. L. Weedon, L. Eberson, Chem. Commun. 1973, 1903.

[42] J. G. Gourcy, M. Holder, B. Terem, J. H. P. Utley, J. Chem. Soc., Chem. Commun. 1976, 779 .

[43] K. Tsujimoto, Y. Kamiyama, Y. Furukawa, M. Ohashi, Bull. Chem. Soc. Jpn. 1983, 56, 351.

[44] L. M. Fragoso-Luna, B. A. Frontana-Uribe, J. Cárdenas, Tetrahedron Lett. 2002, 43, 1151.

[45] J. Voss, Tetrahedron 1971, 27, 3753.

[46] a) D. W. Sopher, J. H. P. Utley, J. Chem. Soc., Chem. Commun. 1981, 134; b) N. Islam, D. W. Sopher, J. H. P. Utley, Tetrahedron 1987, 43 , 959 ; c) N. Islam, D. W. Sopher, J. H. P. Utley, Tetrahedron 1987, 43, 2741; d) K. G. Ellis, N. Islam, D. W. Sopher, J. H. P. Utley, H. L. Chum, M. Ratcliff, J. Electrochem. Soc. 1987, 134, 3058; e) J. H. P. Utley, S. Ramesh, ARKIVOC 2003, xii, 18 .

[47] K. Lam, I. E. Markó, Chem. Commun. 2009, 95.

[48] K. Lam, I. E. Markó, Synlett 2012, 23, 1235.

[49] C.-M. Hu, F.-L. Qing, J. Org. Chem. 1991, 56, 6348.

[50] H. S. Park, H. Y. Lee, Y. H. Kim, Org. Lett. 2005, 7, 3187.

[51] G. N. Varseev, M. E. Maier, Angew. Chem. Int. Ed. 2009, 48, 3685 .

[52] J. J. Xue, X. M. Yu, Chinese Chemical Letters 2011, 22, 761.

[53] J. Cossy, in 'Radicals in Organic Synthesis', Eds. P. Renaud, M. P. Sibi, Wiley-VCH, Weinheim, Germany, 2001, Vol. 1, p. 229 and references therein.

[54] R. Beugelmans, M. T. Le Goffand, H. Compaignon de Marcheville, C. R. Acad Sci Paris 1969, 269, 1309.

[55] a) C. Portella, J. P. Pete, Tetrahedron Lett. 1985, 26, 211; b) C. Portella, M. Iznaden, Tetrahedron 1989, 45,6467

[56] a) H. Deshayes, J. P. Pete, C. Portella, D. Scholler, J. Chem. Soc., Chem. Commun. 1975, 439; b) J. P. Pete, C. Portella, D. Scholler, J. Photochemistry 1984, 27, 128.

[57] a) H. Deshayes, J. P. Pete, C. Portella, Tetrahedron Lett. 1976, 24, 2019; b) C. Portella, H. Deshayes, J. P. Pete, D. Scholler Tetrahedron 1984, 40, 3635

[58] A. Klausener, G. Beyer, H. Leismann, H.D. Scharf, E. Müller, J. Runsink, H. Görner, Tetrahedron 1989, 45, 4989.

[59] a) J. P. Pete, C. Portella, C. Monneret, J.-C. Florent, Q. Khuong-Huu, Synthesis 1977, 774; b) M. Collins, V. R. Z. Munasinghe, J.
Chem. Soc., Chem. Commun. 1977, 927; c) R. Bonjouklian, B. Ganem, Carbohydr. Res. 1979, 76, 245; d) A. Klausener, E. Muller, J. Runsink, H.-D. Scharf, Carbohydr. Res. 1983, 116, 295.

[60] T. Kishi, T. Tsuchiya, S. Umezawa, Bull. Chem. Soc. Jpn. 1979, 52, 3015.

[61] a) R. H. Ball, D. Horton, D. M. Williams, E. Winter-Mihaly, Carbohydr. Res. 1977, 58, 109; b) T. Kishi, T. Tsuchiya, S. Umezawa, Bull. Chem. Soc. Jpn. 1979, 52, 3015.

[62] a) T. Kishi, T. Tsuchiya, S. Umezawa, Bull. Chem. Soc. Jpn. 1979, 52, 3015; b) J. P. Pete, C. Portella, Bull. Soc. Chim. Fr. 1985, 195.

[63] R. K. Murray, Jr., T. M. Ford, J. Org. Chem. 1979, 44, 3504

[64] W. C. Still, M.-Y. Tsai, J. Am. Chem. Soc. 1980, 102, 3654 .

[65] M. Miyashita, N. Chida, A. Yoshikohsi, J. Chem. Soc., Chem. Commun. 1982, 1354.

[66] I. Saito, H. Ikehira, R. Kasatani, M. Watanabe, T. Matsuura, J. Am. Chem. Soc. 1986, 108, 3115.

[67] a) R. E. Ireland, J. D. Armstrong, III, J. Lebreton, R. S. Meissner, M. A. Rizzacasa, J. Am. Chem. Soc. 1993, 115, 7152; b) S. Diethelm, C. S. Schindler, E. M. Carreira, Org. Lett. 2010, 12, 3950 ; c) S. Diethelm, C. S. Schindler, E. M. Carreira, Chem. Eur. J. 2014, 20, 6071.

[68] a) A. Chiocconi, C. Marino, E. Otal, R. M. de Lederkremer, Carbohydr. Res. 2002, 337, 2119; b) A. Bordoni, R. M. de Lederkremer, C. Marino, Carbohydr. Res. 2006, 341, 1788; c) A. Bordoni, R. M. de Lederkremer, C. Marino, Tetrahedron 2008, 64, 1703.

[69] a) D. J. L. Clive, S. Daigneault, J. Chem. Soc., Chem. Commun. 1989, 332; b) D. J. L. Clive, S. Daigneault, J. Org. Chem. 1991, 56, 3801.

[70] M. Suzuki, H. Koyano, R. Noyori, J. Org. Chem. 1987, 52, 5583.

[71] a) A. G. Myers, K. R. Condroski, J. Am. Chem. Soc. 1993, 115, 7926; b) A. G. Myers, K. R. Condroski, J. Am. Chem. Soc. 1995, 117, 3057.

[72] a) J. F. Ambrose, R. F. Nelson, J. Electrochem Soc. 1968, 115, 1159; b) J. F. Ambrose, L. L. Carpenter, R. F. Nelson, J. Electrochem. Soc $\mathbf{1 9 7 5}, 122,876$

[73] D. R. Prudhomme, Z. Wang, C. J. Rizzo, J. Org. Chem. 1997, 62, 8257.

[74] B. Shen, M. W. Bedore, A. Jamison, Chem. Commun. 2012, 48, 7444.

[75] R. Matsubara, Y.-S. Shin, T. Shimada, M. Hayashi, Asian J. Org. Chem. 2014, 3, 1054.

[76] a) M. R. Almond, J. L. Collins, B. E. Reitter, J. L. Rideout, G. A. Freeman, M. H. St Clair, Tetrahedron Lett. 1991, 32, 5745; b) M. Park, C. J. Rizzo, J. Org. Chem. 1996, 61, 6092; c) Z. Wang, D. R. Prudhomme, J. R. Buck, M. Park, C. J. Rizzo, J. Org. Chem. 2000, 65, 5969.

[77] L. Chenneberg, A. Baralle, M. Daniel, L. Fensterbank, J.-P. Goddard, C. Ollivier, $A d v$. Synth. Catal. 2014, 356, 2756.

[78] D. Rackl, V. Kais, P. Kreitmeier, O. Reiser, Beilstein J. Org. Chem. 2014, 10, 2157.

[79] K. Okada, K. Okubo, N. Morita, M. Oda, Tetrahedron Lett. 1992, 33, 7377.

[80] G. L. Lackner, K. W. Quasdorf, L. E. Overman, J. Am. Chem. Soc. 2013, 135, 15342. 